\title{
Биогидроксиапатит - новая фаза для селективного микровзвешивания паров органических соединений - маркеров воспаления в носовой слизи телят и человека Сообщение 1. Сорбция в модельных системах
}

\author{
(C) 2021 Кучменко Т.А. ${ }^{1}$, Умарханов Р.У. ${ }^{1,2}$, Менжулина Д.А. ${ }^{3}$ \\ ${ }^{1}$ Воронежский государственный университет инженерных технологий, Воронеж \\ ${ }^{2} О О О$ «Сенсорика - Новые Технологии», Воронеж \\ ${ }^{3}$ Воронежская детская клиническая больница ВГМУ им. Н.Н. Бурденко, Воронеж
}

Поступила в редакцию 1.03.2021 г.

DOI: $10.17308 /$ sorpchrom.2021.21/3348

В первом сообщении о применении наноструктурированной фазы биогидроксиапатита (ГА) рассмотрены особенности сорбции паров индивидуальных легколетучих органических соединений различных классов на фазах биогидроксиапатита, нанесенных на электроды пьезокварцевых резонаторов объемных акустических волн. Особенность исследования заключается в применении сорбционных фаз малых масс (от 1 до 7 мкг) и прямом взвешивания паров веществ пьезовесами с чувствительностью до $10^{-9}$ г. Установлена зависимость эффективности сорбции ГА к парам выбранных соединений (спирты, кетоны, кислоты, арены, амины) от массы наносимой фазы на ограниченную площадь поверхности электродов пьезорезонаторов. Изучено влияния способа введения паров сорбтивов в зону сорбента (инжекция паров, фронтальная подача). Представлены расчеты изотерм сорбции соединений, позволяющие разработать практические решения либо для высокоселективного детектирования их в смеси, либо для оценки изменения концентрации отдельных компонентов. Установлены особенности сорбции паров органических соединений в широком диапазоне концентраций. Установлено, что в зависимости от массы сорбента в изученном диапазоне сорбция паров меняется от линейной монослойной до многослойной. Рассчитаны селективность и чувствительность сенсоров с фазами ГА разных масс. Показано, что некоторые соединения могут быть количественно определены в смеси паров по сигналам сенсоров с ГА. Пьезосенсоры масс-чувствительного типа с фазой ГА разной массы рекомендованы в качестве измерительных элементов для газоанализаторов и систем интегральной оценки состава сложных смесей соединений малых концентраций по методологии «электронный нос».

Ключевые слова: сорбция, гидроксиапатит, биомолекулы, маркеры воспаления, сенсоры, биопробы, диагностика воспаления, носовая слизь, животные, человек.

\section{Введение}

В настоящее время для улучшения эксплуатационных характеристик газовых сенсоров наиболее перспективны для создания чувствительных слоев наноматериалы разной природы [1]. В химических сенсорах используются различные наноматериалы: от благородных металлов ( $\mathrm{Au}, \mathrm{Ag})$; магнитных $\left(\mathrm{Fe}_{3} \mathrm{O}_{4}\right.$, $\mathrm{Fe}_{3} \mathrm{~S}_{4}, \gamma-\mathrm{Fe}_{2} \mathrm{O}_{3}, \mathrm{MO} \cdot \mathrm{Fe}_{2} \mathrm{O}_{3}$, где $\mathrm{M}=\mathrm{Ni}, \mathrm{Co}$, $\mathrm{Zn}, \mathrm{Mn}, \mathrm{Mg}$ ), полупроводниковых материалов (CdS, CdSe, CdTe, ZnSe, PbS, $\mathrm{PbTe})$ до квантовых точек $(\mathrm{CdS})$ и пленок Лэнгмюра-Блоджетт. Наноматериалы широко применяют в качестве главной составляющей различных химических и биологических сенсоров. Сенсо- 
ры на наноматериалах применяются при экспресс-анализе сложных систем. Сенсоры выполняют функцию передачи, фиксирования и обработки информации о системах, например, химическом составе, положении и динамике изменения, а также строении вещества. В настоящее время значительно изменяются функции, выполняемые сенсорами. В основном, это характерно для интегральных сенсоров, которые могут включать в свой состав дополнительные устройства. Такие сенсоры применяют для создания измерительных систем, которые осуществляют сбор, обработку, хранение и распределение информации [2].

Современные сенсоры должны соответствовать следующим требованиям [3]:

1) Высокие качественные характеристики (селективность, точность, воспроизводимость показаний);

2) высокая надежность (длительный срок службы, устойчивость к внешней среде);

3) технологичность (малые габариты и масса, простота конструкции, интегральное исполнение, низкая себестоимость);

4) малое время сорбции и десорбции ключевых аналитов.

Действие химических сенсоров основано как на химических реакциях, так и на изменении физических характеристик. В случае, когда в основе химических сенсоров лежит химическая реакция, аналитический сигнал зависит от химического взаимодействия определяемого компонента с чувствительным слоем. Во втором случае измеряется физический параметр (коэффициент поглощения или отражения света, масса, проводимость и др.) [4].

Химические сенсоры являются важным элементом при разработке сенсорных анализаторов, которые предназначены для определения какого-либо вещества или смеси веществ в определенном диапазоне концентраций. На данный момент актуальным является создание газовых сенсоров на основе наноструктурированных материалов [5-9]. На основании того, что наноматериалам свойственны усовершенствованные физикохимические свойства, их применение повышает выходные характеристики сенсора [10]. Огромное количество наночастиц встраиваются в органические и неорганические матрицы. В результате создаются наносенсоры, которые используют чаще для анализа газовых сред, реже для жидких. Каждое наноструктурированное покрытие характеризуется определенными достоинствами и недостатками, поэтому при выборе наноматериалов для создания химических газовых сенсоров нужно ознакомиться с его особенностями.

\section{Теоретическая часть}

В качестве объекта исследования выбран биогидроксиапатит $\mathrm{Ca}_{5}\left(\mathrm{PO}_{4}\right)_{3} \mathrm{OH}$. Замещение анионов в структуре гидроксиапатита на гексагональной оси приводят к изменениям межатомных расстояний в структуре, различным искажениям фосфатных тетраэдров, вариациям параметров элементарной ячейки, что сказывается на его физико-химических и сорбционных свойствах.

В результате зонтичного поиска и анализа публикаций по ключевым словам: «наноматериалы, сенсоры, гидроксиапатит, анализ» в период с 2008 по 2020 гг. установлена устойчиво растущая тенденция изменения числа публикаций по этим запросам, особенно резко в период с 2014-2016 г. (рис. 1). Тенденция роста публикаций в этом направлении сохраняется и сейчас.

До 2015 года применение гидроксиапатита в качестве сорбента при решении аналитических задач не упоминается.

Цель работы - изучить сорбционные свойства микрофаз на основе биогидроксиапатита по отношению к легколетучим органическим соединениям разных классов и оценить перспективность их применения для разработки высокочув- 


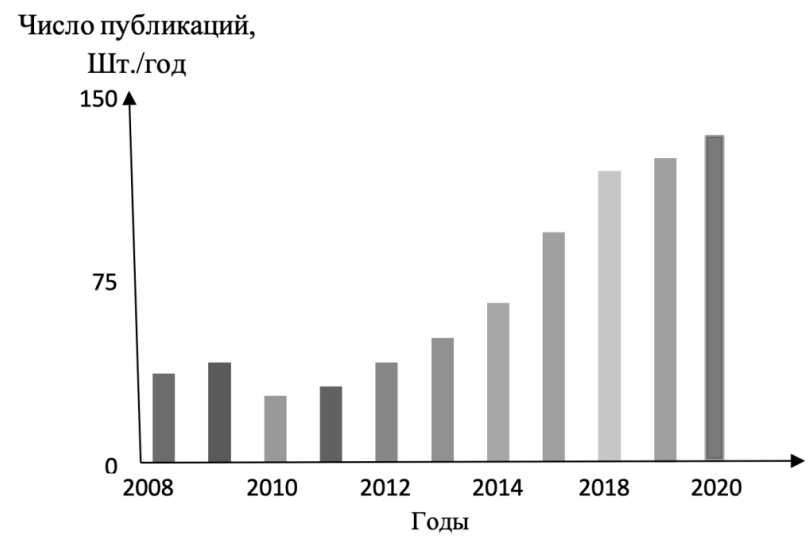

Рис. 1. Изменение числа публикаций в научной литературе по итогам зонтичного поиска по ключевому набору слов: «наноматериалы, сенсоры, гидроксиапатит, анализ»

Fig. 1. Changes in the number of publications in scientific literature based on the results of an umbrella literature search for a key set of words: "Nanomaterials, sensors, hydroxyapatite, analysis"

ствительных пьезосенсоров, новых средств и методик анализа газовых смесей, в том числе выделяемых биопробами человека и животных.

\section{Экспериментальная часть}

Основным методом в работе является пьезокварцевое микровзвешивание; прибор - многоканальные нановесы «MCNanoW-PQ» (OOO «Сенсорика Новые Технологии», Россия) с 8-мью рабочими каналами. Для изготовления пьезосенсоров применяли пьезокварцевые резонаторы (ПКР) с базовой частотой колебания 10.0 и 14.0-15.0 МГц. Многоканальные нановесы связаны с программным обеспечением «MCWSoft», позволяющем регистрировать изменения массы, прикрепленной к электродам фазы, в режиме реального времени с шагом 1 с и чувствительностью до 1 нг.

Многоканальные нановесы оснащены герметичной ячейкой из фторопласта объемом $60.0 \mathrm{~cm}^{3}$ с крышкой и патрубками для ввода паров, как индивидуальных соединений, так и их смесей в разных режимах - фронтальном, инжекторном. Сорбцию проводили при температуре $20.0 \pm 0.5^{\circ} \mathrm{C}$.

Общая схема измерения массы сорбата легколетучих соединений в инжекторном режиме заключалась в сле- дующем: пробу индивидуального вещества объемом $5.0 \mathrm{~cm}^{3}$ помещали в стеклянный герметичный сосуд, который закрывали мягкой полимерной мембраной и выдерживали 20-30 мин при температуре $20 \pm 1^{\circ} \mathrm{C}$ до установления равновесия в системе «жидкость - пар». После установления равновесия отбирали определенный объем $\left(V_{P Г \Phi}, \mathrm{cm}^{3}\right)$ равновесной газовой фазы (РГФ) вещества индивидуальным шприцем и вводили в ячейку со скоростью $1 \mathrm{~cm}^{3} /$ сек. Массовую концентрацию паров веществ в ячейке детектирования $\left(c, \Gamma / \mathrm{M}^{3}\right)$ изменяли, варьируя объем РГФ от 0.5 до $5.0 \mathrm{~cm}^{3}$ шагом $0.5 \mathrm{~cm}^{3}$. Каждая точка воспроизводилась не менее 5-7 раз для повышения метрологической надежности расчетов. После проверки стабильности системы и запуска старта измерения пары напускали в околосенсорное пространство. Они сорбируются на фазах ГА, нанесенных на электроды ПКР, что приводит к изменению частоты колебаний кварцевой пластины. Применяли также фронтальный ввод паров в ячейку детектирования в статических условиях (без газаносителя) за счет самопроизвольной диффузии паров в околосенсорное пространство от источника (проба индивидуального соединения) в закрытом корпусе насадки.

Для расчета параметров сорбции применяли количественный сигнал пьезо- 
Таблица 1. Микроструктурные характеристики покрытия ГА различных масс (единичная партия)

Table 1. Microstructural characteristics of the HA coating of various mass (single batch)

\begin{tabular}{|c|c|c|}
\hline Масса покрытий, мкг & Средний диаметр зерен $\mathrm{d}_{\mathrm{cp}}$, нм & Шероховатость $\mathrm{S}_{\mathrm{q}, ~ н м}$ \\
\hline 2.03 & 415 & 544 \\
\hline 4.17 & 215 & 111 \\
\hline 5.03 & 187 & 97 \\
\hline
\end{tabular}

весов с сорбентом - максимальное изменение частоты колебаний пьезосенсора $\left(-\Delta F_{\max }\right.$, Гц), характеризующее эффективность сорбции органических соединений на фазах сорбента, пропорционально массе сорбата $\Delta \mathrm{m}$ (мкг) по модели Зауэрбрея на электродах пьезосенсора в любой момент времени сорбции. По этой модели рассчитывали также массу фаз сорбента на электродах пьезовесов ( $\mathrm{m}_{\Gamma \mathrm{A}}$, МКг).

В качестве сорбента изучена фаза гидроксиапатита (ГА), нанесенная на поверхность электродов ПКР. Гидроксиапатит (ГА) $\mathrm{Ca}_{5}\left(\mathrm{PO}_{4}\right)_{3} \mathrm{OH}$ получен по золь-гель методике, разработанной в ННГУ им. Н.И. Лобачевского [11]. Данная методика была оптимизирована для получения наночастиц с хорошими сорбционными свойствами путем варьирования концентрации реагентов.

На основании того, что гидроксиапатит, синтезированный по золь-гель методу, является наноструктурированным материалом, совместимым с биологическими тканями, были предположены его особые сорбционные свойства по отно- шению к легколетучим биомолекулам, которые выделяются в процессе жизнедеятельности живых организмов. В качестве сорбтивов изучены пары индивидуальных соединений квалификации «ч.д.а.» (ООО «Реахим», Россия): спирты алифатические $\mathrm{C}_{2}-\mathrm{C}_{5}$, нормального и изомерного строения; кетоны (ацетон, метилэтилкетон, МЭК), арены (бензол, толуол, фенол), амины (метиламин, диэтиламин), $\mathrm{C}_{2}, \mathrm{C}_{4}, \mathrm{C}_{5}$-кислоты алифатические; хлороформ, алкилацетаты $\mathrm{C}_{2}-\mathrm{C}_{5}$, ацетальдегид. В качестве основного мешающего вещества применяли воду (бидистиллят с контролем по электропроводности).

Для изменения, регулирования чувствительности и селективности микровзвешивания паров органических веществ на электроды пьезокварцевого резонатора, обезжиренные ацетоном или хлороформом, равномерно наносили фазы сорбентов изацетона (0.5 г фазы/10 $\mathrm{cm}^{3}$ ) методом погружения в У3суспензию [12]. Массу фаз от 1 до 7 мкг варьировали путем изменения времени экспозиции резонаторав суспензии (от 5

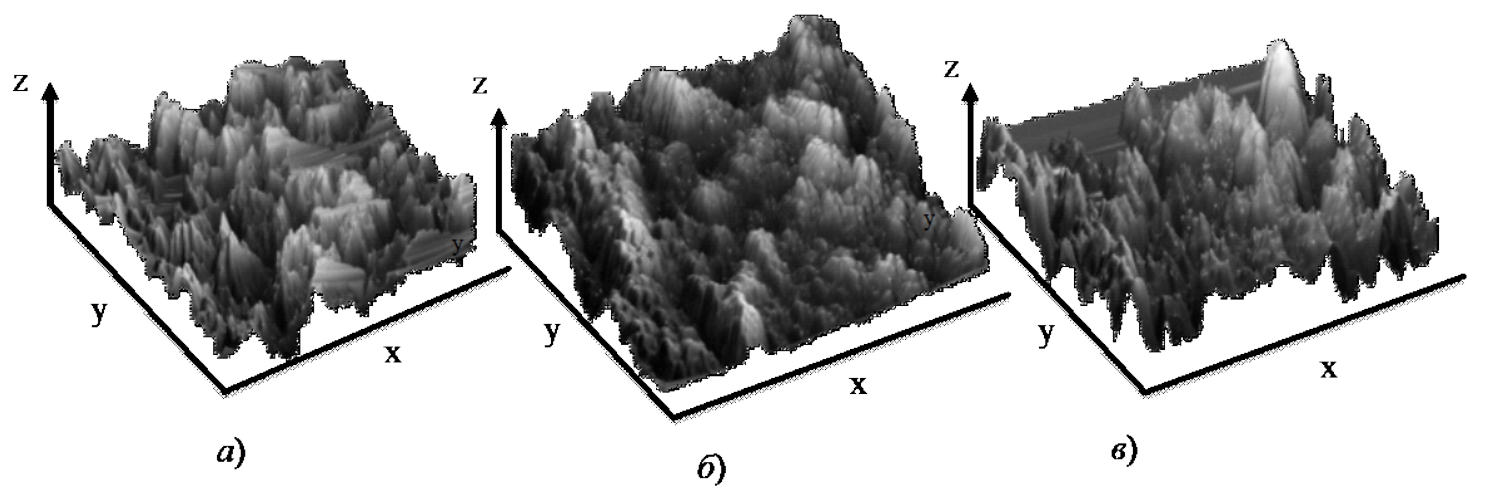

Рис. 2. 3D-изображение фаз ГА массой $\mathrm{m}=2.03$ мкг (a); 4.17 мкг(б); $\mathrm{m}=5.03$ мкг (в) (разрешение: 30х30 мкм).

Fig. 2. 3D image of HA phases with mass $\mathrm{m}=2.03 \mu \mathrm{g}(a) ; 4.17 \mu \mathrm{g}(b) ; \mathrm{m}=5.03 \mu \mathrm{g}(c)$ (resolution: 30x30 $\mu \mathrm{m}$ ). 
до 15 с). Свободный растворитель удаляли в сушильном шкафу (40 минут при $\mathrm{t}$ от $\left.50^{\circ} \mathrm{C}\right)$, располагая ПКР в держателе вертикально.

\section{Обсуждение результатов}

На первом этапе изучили особенности сорбционных свойств фазы разной массы. Для обоснования и объяснения зависимости сорбционных свойств ГА от массы фазы на электродах ПКР в ЦКП ФГБОУ ВО «ЛГТУ» на атомно-силовом микроскопе «Solver P447-PRO» с системой видеонаблюдения исследована микроструктура покрытий ГА (рис. 2).

По полученным изображениям рассчитаны средний диаметр зерен и шероховатость (табл. 1).

При увеличении массы покрытия уменьшается средний диаметр зерен и шероховатость, фаза становится более однородной и гладкой. Приращение массы покрытия ГА более 4 мкг не приводит к значительным изменениям средних размеров зерен на поверхности и шероховатости. Это позволяет прогнозировать воспроизводимость и близкие сорбционные свойства фаз при незначительных изменениях масс покрытий более 4 мкг, что важно при промышленном изготовлении сенсоров с воспроизводимыми, повторяющимися свойствами.

На примере нескольких биомолекул различной полярности изучена зависи- мость максимального отклика пьезовесов с ГА в парах в широком диапазоне масс покрытия (рис. 3).

Отклик сенсора в парах всех трех соединений зависит от массы ГА, но фазы малых (1-2 мкг) и больших масс (более 7 мкг) одинаково не эффективно реагируют на пары соединений. При этом независимо от разницы в концентрации и природе веществ, эффективность микровзвешивания паров равная. Наибольшее различие в откликах сенсора на пары воды, этанола и ацетона характерны для массы ГА 3.5-4.5 мкг. При этом характер изменения чувствительности микровзвешивания паров от массы фазы идентичен для этанола и ацетона, но сильно отличается для воды. Это объясняется наибольшим сродством ГА к парам воды. Установлены различия в изменении скорости прироста эффективности сорбции паров воды, этанола и ацетона при изменении массы покрытия. Так, фазы ГА массой меньше 2 мкг и больше 6 мкг эффективно сорбируют воду и одинаково неэффективно спирт и ацетон. Фазы массой 3.5-4.0мкг сорбируют этанол и воду, в меньшей степени ацетон. При нанесении фазы более 4.5 мкг эффективнее сорбируется этанол, чем вода и ацетон. Эти различия позволяют по отношению сигналов сенсоров с разными массами фазы ГА распознать в смеси этих трех соединений каждое и

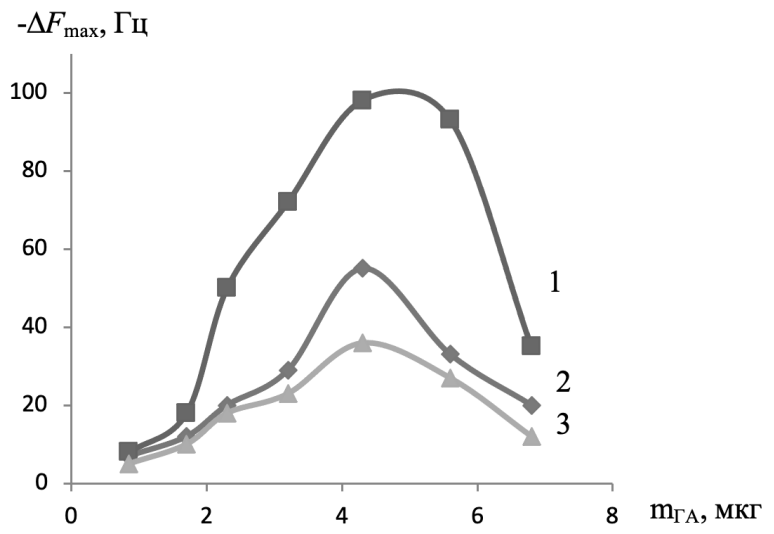

Рис. 3. Зависимость максимального отклика сенсоров от массы ГА на электродах в парах: воды (1), этанола (2), ацетона (3).

Fig. 3. Dependence of the maximum response of sensors on the HA mass on electrodes in vapours: water (1), ethanol (2), acetone (3). 

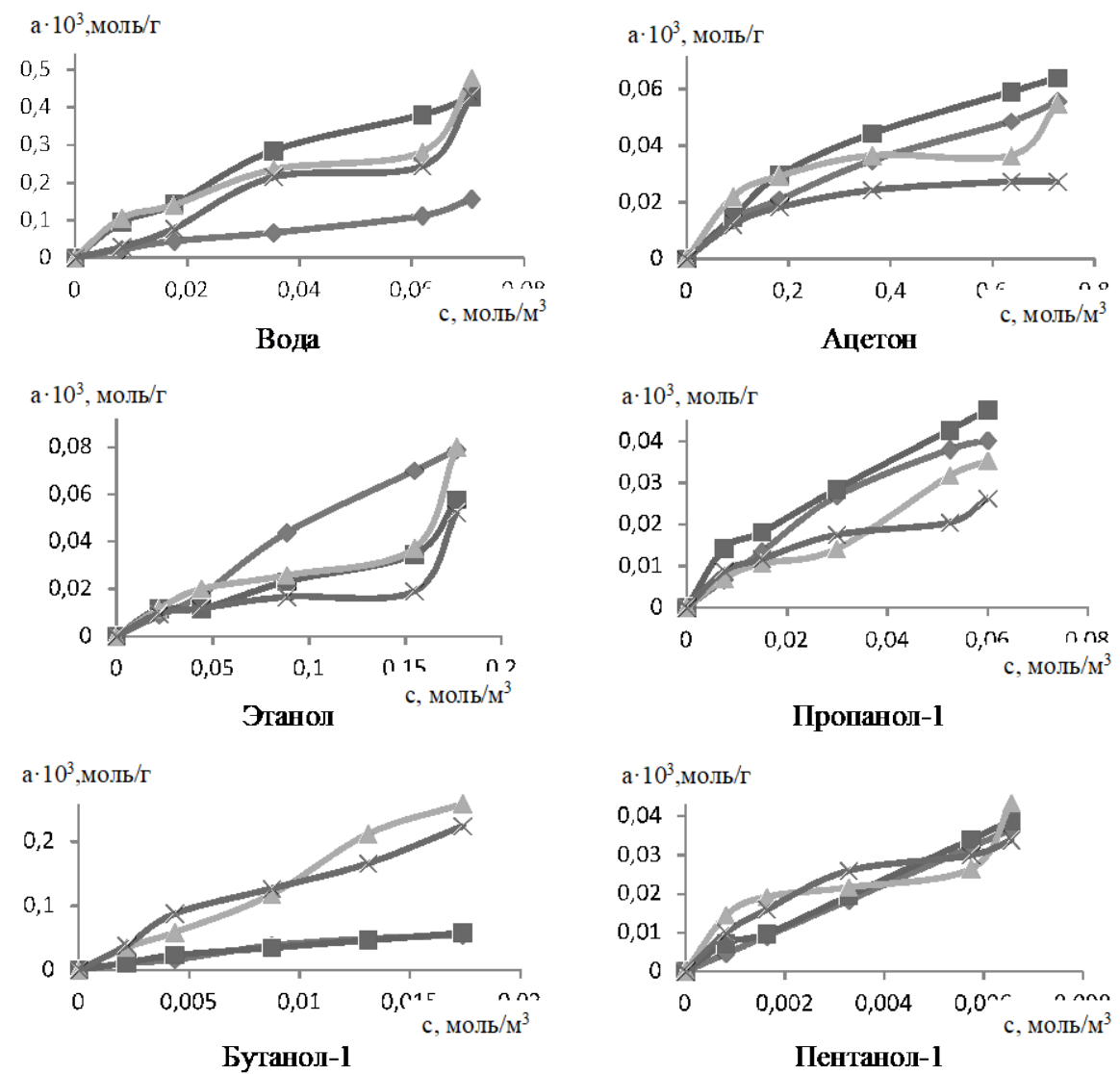

Рис. 4. Изотермы сорбции паров некоторых веществ на фазе ГА разных масс

Fig.4. Sorption isotherms of vapours of some substances on the HA phase of different mass

них них без разделения. Т.е. применение одного, даже эффективно сорбирующего все пары, сенсора с фазой ГА массой 2.54.0 мкг не позволит различить пары без разделения, в то время как сочетание сенсоров с разными массами позволит говорить о присутствии этих компонентов отдельно. Для оценки различий свойств фаз ГА построены изотермы сорбции (рис. 4).

Для одной и той же сорбционной системы форма изотермы для фаз ГА разной массы меняется от линейной до $\mathrm{S}$ образной. В связи с этим невозможно описать кривые одной теорией: линейные изотермы описывали по теории Лэнгмюра, коэффициенты линейных уравнений приведены в табл. 2. По полученным изотермам сложно анализировать особенности механизма взаимодействия даже гомологов на однотипной фазе сорбента. Именно различия в характере изотерм для одного сорбтива при разных характеристиках поверхности сорбента позволяют проследить изменения в заполнении пор разной неидеальной геометрии фазы.

Коэффициент Генри $K_{a}$, Гцдм ${ }^{3} /$ моль приоритетная характеристика рассматриваемых систем, поскольку характеризует чувствительность пьезосенсоров к определенному виду паров.

Установлено, что значения коэффициента $K_{a}$ для паров воды, бутанола-1 зависят от массы фазы сорбента, в то время как для других соединений в пределах погрешности чувствительности микровзвешивания не различимы или меняются незначительно.Особенно резко меняется сродство к молекулам бутанола-1 на фазах ГА малых (1-2 мкг) и больших масс (4-5 мкг). Если учесть, что также резко меняется шероховатость поверхности фазы ГА (табл. 1), то можно утверждать, что для линейной молекулы спирта параметры поверхности являются основополагающими при сорбции. При увеличении числа атомов углерода в алкильном радикале спирта чувствительность микровзвешивания растет. 
Таблица 2. Характеристики линейной корреляции сорбции паров органических соединений и воды на фазах ГА

Table 2. Characteristics of the linear correlation of the sorption of organic compound vapours and water on the HA phases

\begin{tabular}{|c|c|c|c|c|c|}
\hline \multirow[b]{2}{*}{ Сорбтивы } & \multirow[b]{2}{*}{$\begin{array}{l}\text { Масса плен- } \\
\text { ки, } \text { ІГА, мкг }\end{array}$} & \multicolumn{2}{|c|}{ Модель Лэнгмюра } & \multicolumn{2}{|c|}{ Модель БЭТ } \\
\hline & & $\begin{array}{c}\text { Коэффициент } \\
\text { уравнения } K_{a} \text {, } \\
\text { Гцд }{ }^{3} / \text { моль }\end{array}$ & $\begin{array}{c}\text { Коэффи- } \\
\text { циент } \\
\mathrm{R}^{2}\end{array}$ & 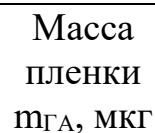 & $\begin{array}{c}\text { Константа } \\
C_{\text {бэт } Г ц д \mathbf{M}^{3} / \text { моль }}\end{array}$ \\
\hline \multirow{2}{*}{ Вода } & 1.03 & 6.4 & 0.95 & 4.17 & 32 \\
\hline & 2.15 & 2.0 & 0.97 & 5.03 & 16 \\
\hline \multirow{3}{*}{ Этанол } & \multirow{3}{*}{2.15} & \multirow{3}{*}{4.5} & \multirow{3}{*}{0.99} & 1.03 & 5.4 \\
\hline & & & & 4.17 & 8.9 \\
\hline & & & & 5.03 & 20 \\
\hline \multirow{2}{*}{ Пропанол-1 } & 1.03 & 7.3 & 0.97 & 4.17 & 8.5 \\
\hline & 2.15 & 6.8 & 0.98 & 5.03 & 52 \\
\hline \multirow{2}{*}{ Пропанол-2 } & 4.03 & 28 & 0.99 & 1.03 & 15 \\
\hline & 5.03 & 16 & 0.95 & 2.19 & 7.2 \\
\hline \multirow{4}{*}{ Бутанол-1 } & 1.03 & 36 & 0.96 & \multirow{4}{*}{ - } & \multirow{4}{*}{ - } \\
\hline & 2.15 & 35 & 0.95 & & \\
\hline & 4.03 & 15 & 0.99 & & \\
\hline & 5.03 & 13 & 0.96 & & \\
\hline \multirow{2}{*}{ Бутанол-2 } & 1.03 & 12 & 0.96 & 4.17 & 38 \\
\hline & 2.15 & 10 & 0.95 & 5.03 & 57 \\
\hline \multirow{2}{*}{ Пентанол-1 } & 1.03 & 59 & 0.99 & 4.17 & 98 \\
\hline & 2.15 & 56 & 1.00 & 5.03 & 34 \\
\hline \multirow{2}{*}{ Ацетон } & 1.03 & 0.7 & 0.94 & 4.17 & 2.1 \\
\hline & 2.15 & 0.8 & 0.94 & 5.03 & 1.4 \\
\hline \multirow{3}{*}{ Диэтиламин } & 2.15 & 0.4 & 0.94 & \multirow{3}{*}{1.03} & \multirow{3}{*}{1.1} \\
\hline & 4.03 & 0.4 & 0.96 & & \\
\hline & 5.03 & 0.2 & 0.98 & & \\
\hline \multirow{4}{*}{ Бензол } & 1.03 & 0.21 & 0.97 & \multirow{4}{*}{ - } & \multirow{4}{*}{ - } \\
\hline & 2.15 & 0.22 & 0.98 & & \\
\hline & 4.03 & 0.20 & 0.96 & & \\
\hline & 5.03 & 0.10 & 0.98 & & \\
\hline \multirow{4}{*}{ Фенол } & \multirow{4}{*}{-} & \multirow{4}{*}{ - } & \multirow{4}{*}{ - } & 1.03 & 2191 \\
\hline & & & & 2.19 & 3161 \\
\hline & & & & 4.17 & 2777 \\
\hline & & & & 5.03 & 1282 \\
\hline \multirow{3}{*}{ Хлороформ } & \multirow{3}{*}{-} & & & 1.03 & 2.4 \\
\hline & & - & - & 2.15 & 2.8 \\
\hline & & & & 4.17 & 4.0 \\
\hline
\end{tabular}

Уменьшение полярности молекул спирта с ростом длины алкильного радикала снижает эффект водородных связей при сорбции, но при этом именно на более шероховатой поверхности фаз малых масс эффективнее сорбируются тяжелые спирты (рис. 5).

Полученная корреляция для ряда спиртов устойчива и согласуется с теоретическими основами пьезокварцевого микровзвешивания. Характер изменения чувствительности пьезовесов с ГА малой массы позволяет прогнозировать увеличение чувствительности с дальнейшим ростом алкильного радикала в молекуле спирта. Однако для анализа живых систем это не является важным, поскольку присутствие тяжелых спиртов в них маловероятно. 


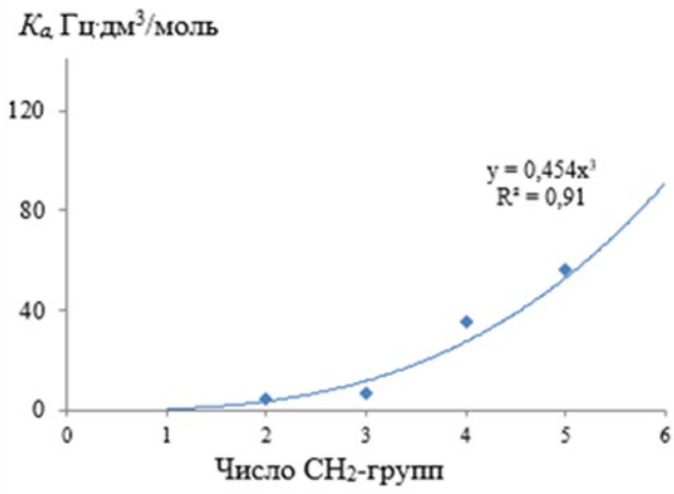

Рис. 5. Зависимость чувствительности пьезовесов с фазой ГА массой 2.1 мкг к парам алифатических спиртов нормального строения от длины алкильного радикала в молекуле

Fig. 5. Dependence of the sensitivity of piezo balance with a HA phase with mass of $2.1 \mu \mathrm{g}$ to vapours of normal aliphatic alcohols on the length of the alkyl radical in the molecule

Для фазы сорбента малых масс разные коэффициенты Генри для фенола (1-2 мкг) чувствительность мик- и бензола на фазах малых и больших ровзвешивания паров веществ снижается масс позволяют говорить о независимом в ряду: спирты > вода > ацетон >диэти- детектировании фенола при совместном ламин $>$ бензол. В этом ряду просматривается закономерность вклада во взаимодействие с сорбентом алкильных радикалов с большей полярностью и компактной структурой и ОН-групп. Для фаз сорбента больших масс (4-5 мкг) эффективность микровзвешивания снижается в ряду:

фенол $>>$ спирты $>$ вода $>$ хлороформ $>$ $>$ ацетон $>$ бензол $>$ диэтиламин.

Доминирующим становится вклад как $\pi-\pi$ сопряжения бензольного кольца, так и влияние полярности молекул. Ряды массовой чувствительности для фаз биогидроксиапатита малых и больших масс не идентичны. Это подтверждает участие в сорбции не только основных химических центров сорбции, но и пор, каналов, шероховатости поверхности фаз ГА в большей степени, чем для карбоксилированных углеродных нанотрубок и полимерных сорбентов. В отличие от МУНТ, например, увеличение числа химических центров сорбции на фазе ГА ограниченной поверхности и объема существенно влияет на их пространственную доступность и морфологию поверхности и, как следствие, на чувствительность микровзвешивания. Особенно сильно это просматривается в изотоническом ряду аренов. Так существенно присутствии их в широком диапазоне содержаний.

Для паров фенола не удается получить линейных изотерм ни на малых, ни на больших по массе фазах ГА (рис. $2 a$ ). Особенность сорбции фенола ранее неоднократно обсуждалась и проявляется независимо от природы сорбента. Многослойная медленная сорбция протекает на хроматографических фазах [13]. Не стали исключением и твердофазных сорбенты: многослойные углеродные нанотрубки не окисленные и окисленные [14], нитрат оксида циркония [15]. Для оценки вклада в сорбцию на фазах ГА ОН-группы сопоставим характер изменения изотерм сорбции фенола и бензола (рис. 6).

Изотермы адсорбции бензола в широком диапазоне концентраций линейны, для фенола характерна во всех системах накопительная сорбция. Закономерно, что для фенола и бензола идентично снижается эффективность сорбции и чувствительность микровзвешивания с ростом массы фазы сорбента и снижением доступности полярных групп и атомов ГА. Это отличает арены от алифатических спиртов. При этом влияние массы фазы ГА на чувствительность микровзвешивания для спиртов, кетонов более 


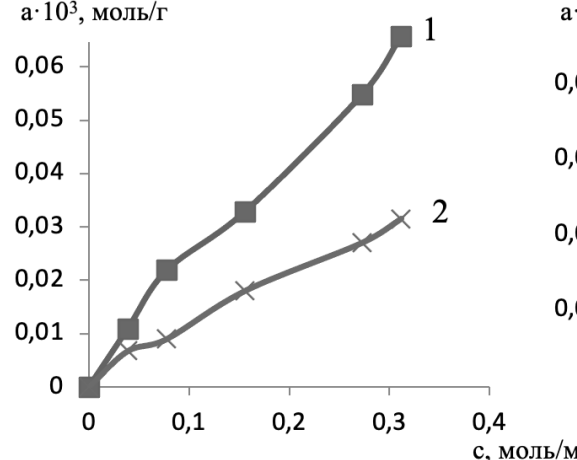

a)

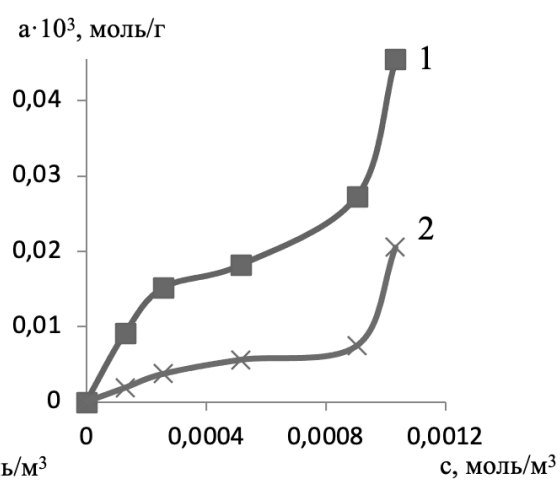

б)

Рис. 6. Изотермы сорбции паров бензола (a) и фенола (б) на фазах ГА массой 1.03 (1) и 5,03 (2) мкг

Fig. 6. Sorption isotherms of benzene vapours $(a)$ and phenol $(b)$ on HA phases with weights of 1.03 (1) and 5.03 (2) $\mu \mathrm{g}$

заметно и значимо, чем для антропогенных веществ - фенола, бензола, хлороформа.

Для оценки эксплуатационных свойств нанофаз ГА оценена молярная селективность микровзвешивания относительно паров воды сенсоров при инжекционном и фронтальном вводе пробы (рис. 7)

Значительные изменения селективно- сти сорбции характерны для покрытий биогидроксиапатита разных масс. Это объясняется существенным равнозначным вкладом всех видов сорбции в поры (нано-, мезо-, микро-) и хемосорбции за счет дисперсионных индукционных взаимодействий, связей с атомами ГА (O, P). С ростом массы фаз ГА средний диаметр зерен уменьшается и снижается шероховатость, но при этом вклад хемо-

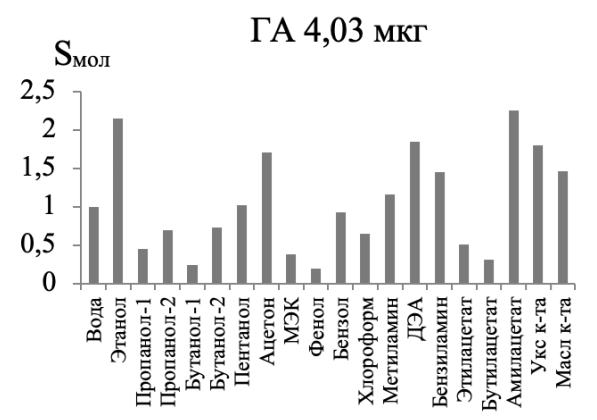

a)

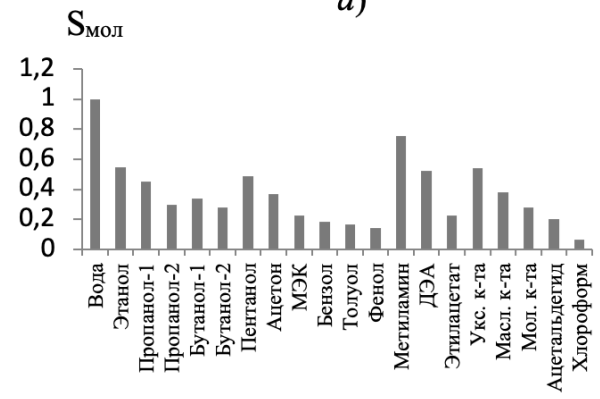

в)

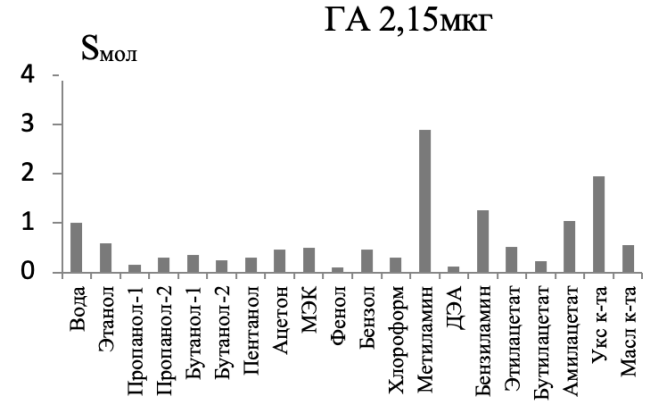

б)

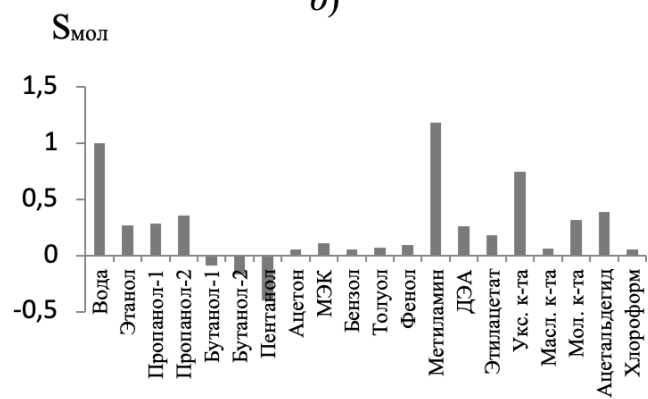

2)

Рис. 7. Молярная чувствительность микровзвешивания относительно паров воды при инжекционном $(a, \sigma)$ и фронтальном $(b, 2)$ вводе проб в зону сенсоров с твердотельными фазами разных масс в закрытую ячейку детектирования

Fig. 7. The molar sensitivity of microweighing relative to water vapour with injection $(a, b)$ and frontal $(c, d)$ sample injection to the area of sensors with solid-state phases of different masses into a closed detection cell 
сорбции остается большим.

Значимо влияет на избирательность и способ напуска паров - инжекционный или фронтальный. Установлено, что при инжекционном вводе паров изученных соединений фаза ГА массой 4.03 мкг наиболее селективна к парам этанола, ацетона, аминов, амилацетата, и кислот, а фаза массой 2.15 мкг - к парам метиламина, бензиламина, уксусной кислоты.
При фронтальном режиме ввода паров явная селективность отмечена для большего числа биомолекул при сорбции на фазе ГА малой массы, чем на фазе ГА большей массы.

Особенности сорбции паров органических соединений при разном способе напуска паров в ячейку детектирования и возможности их идентификации без разделения в смеси рассмотрены в сообщении 2.

Работа выполнена при финансовой поддержке гранта РНФ № 18-76-10015.

\section{Список литературы}

1. Корнев А.С. // Российский химический журнал. 2011. Т. 112. № 6. С. 94-101.

2. Rajneesh M. // BARC Newslett. 2009. No 297. pp. 240-245.

3. Kai S., Haiqing W., Ping L., Zhigang F. // Chin. J. Chem. Eng. 2008. No 4. pp. 584-589.

4. Ionescu R., Llobet E., Reyes L., Smulko J. // Phys. status solidi B. 2008. No 11. pp. 43314335.

5. Smith N., Hong Z., Asher S. // Analyst. 2014. No 24. pp. 6379-6386.

6. Щедрин А.В. // Справ. инж. 2013. № 5. C. 51-72.

7. Слепнева М.А. Дисс. канд. техн. наук. M. 2010.215 c.

8. Умарханов Р.У. Дисс. канд. хим.наук. Воронеж. 2013. 233 с.

9. GuozhenF., GuiyangL., YukunY., Shuo W. // Sensors and Actuators. B 2016. 230. pp. 272280.
10. Вершинин Н.Н., Алейников Н.Н., Ефимов О.Н., Гусев А.Л.// Международный научный журнал альтернативная энергетика и экология. 2009. С. 10-15.

11. Буланов Е.Н. Получение и исследование наноструктурированных биосовместимых материалов на основе гидроксиапатита. Нижний Новгород. 2012. 103 с.

12. Коренман Я.И., Силина Ю.Е., Кучменко Т.А. Патент РФ. № 2259007. 2004.

13.Кучменко Т.А., Умарханов Р.У. Патент РФ. № 2259007. 2012.

14. Кучменко Т.А., Умарханов Р.У. // Журнал аналитической химии. 2013. Т. 68. № 4. C. $397-405$.

15. Кучменко Т.А., Умарханов Р.У., Кочетова Ж.Ю., Бельских Н.В. // Журнал аналитической химии. 2012. Т. 67. № 11. С. 10321039.

\title{
Biohydroxyapatite is a new phase for the selective microweighing of organic compound vapours - markers of inflammation in the nasal mucus of calves and humans Report 1. Sorption in model systems
}

\author{
(C) 2021 Kuchmenko T.A. ${ }^{1}$, Umarkhanov R.U. ${ }^{1,2}$, Menzhulina D.A. ${ }^{3}$ \\ ${ }^{1}$ Voronezh State University of Engineering Technologies, Voronezh, Russian Federation \\ ${ }^{2}$ OOO Sensorica - New Technologies, Voronezh, Russian Federation \\ ${ }^{3}$ Voronezh Children's Clinical Hospital of Voronezh State Medical University named after N.N. Burdenko, \\ Voronezh, Russian Federation
}

Abstract: In the first part of this article on the use of the nanostructured phase of biohydroxyapatite (HA), the features of the sorption of vapours of individual volatile organic compounds of various classes on the phases of biohydroxyapatite deposited on the electrodes of piezoquartz resonators of bulk acoustic waves are considered. The peculiarity of the study is the use of sorption phases of small weights (from 1 to $7 \mu \mathrm{g}$ ) 
and direct weighing of vapours of substances with piezoelectric balances with a sensitivity of up to $10^{-9} \mathrm{~d}$. The dependence of the efficiency of sorption of HA to vapours of the selected compounds (alcohols, ketones, acids, arenes, amines) on the mass of the applied phase on a limited surface area of the electrodes of the piezoresonators has been established. The influence of the method for introducing sorbent vapours into the sorbent zone (vapour injection, frontal supply) has been studied. Calculations of the sorption isotherms of compounds, allowing to develop practical solutions either for highly selective detection of them in a mixture, or for assessing changes in the concentration of individual components, are presented. The features of the sorption of organic compounds vapours over a wide range of concentrations have been established. It was found that, depending on the mass of the sorbent in the studied range, vapour sorption varies from linear monolayer to multilayer. The selectivity and sensitivity of sensors with HA phases of different weights were calculated. It has been shown that some compounds can be quantitatively determined in a vapour mixture by signals from sensors with HA. Piezosensors of mass-sensitive type with HA phase of different masses are recommended as measuring elements for gas analysers and systems for the integral assessment of the composition of complex mixtures of compounds of low concentrations according to the "electronic nose" methodology.

Keywords: sorption, hydroxyapatite, biomolecules, markers of inflammation, sensors, bioassays, diagnostics of inflammation, nasal mucus, animals, humans.

\section{References}

1. Kornev A.S., Rossijskij khimicheskij zhurnal, 2011, Vol. 112, No 6, pp. 94-101.

2. Rajneesh M., BARC Newslett, 2009, No 297, pp. 240-245.

3. Kai S., Haiqing W., Ping L., Zhigang F., Chin. J. Chem. Eng., 2008, No 4, pp. 584-589.

4. Ionescu R., Llobet E., Reyes L., Smulko J., Phys. status solidi B, 2008, No 11., pp. 43314335 .

5. Smith N., Hong Z., Asher S., Analyst, 2014, No 24, pp. 6379-6386.

6. Shhedrin A.V., Sprav. inzh., 2013, No 5, pp. 51-72.

7. Slepneva M.A., Diss. kand. tekhn. nauk., M., 2010, 215 p.

8. Umarhanov R.U., Diss. kand. khim. nauk, Voronezh, 2013, 233 p.

9. Guozhen F., Guiyang L., Yukun Y., Shuo W., Sensors and Actuators. B, 2016, 230, pp. 272-280.

Кучменко Татьяна Анатольевна - д.Х.н., профессор, профессор РАН, заведующая кафедрой физической и аналитической химии ВГУИТ, Воронеж

Умарханов Руслан Умарханович - к.Х.н., доцент кафедры физической и аналитической химии ВГУИТ, директор ООО «Сенсорика - Новые Технологии», Воронеж

Менжулина Дарья Александровна - педиатр, эндокринолог Воронежской детской клинической больницы ВГМУ им. Н.Н. Бурденко, Воронеж
10. Vershinin N.N., Alejnikov N.N., Efimov O.N., Gusev A.L., Mezhdunarodnyj nauchnyj zhurnal al'ternativnajaj energetika $i$ jekologija, 2009, pp. 10-15.

11. Bulanov E.N., Poluchenie i issledovanie nanostrukturirovannyh biosovmestimyh materialov na osnove gidroksiapatita, Nizhnij Novgorod, 2012, $103 \mathrm{p}$.

12. Korenman Ya.I., Silina Yu.E., Kuchmenko T.A., Patent RF, No 2259007, 2004.

13. Kuchmenko T.A., Umarhanov R.U., Patent RF, No 2259007, 2012.

14. Kuchmenko T.A., Umarhanov R.U., Zhurnal analiticheskoj khimii, 2013, Vol. 68, No 4, pp. 397-405.

15. Kuchmenko T.A., Umarhanov R.U., Kochetova Zh.Yu., Bel'skih N.V., Zhurnal analiticheskoj khimii, 2012, Vol. 67, No 11, pp. 1032-1039.

Kuchmenko Tatiana A. - Doctor of Chemistry, Professor of the Russian Academy of Sciences, Head of the Department of Physical and Analytical Chemistry of VSUIT, Voronezh, E-mail: tak1907@mail.ru

Umarkhanov Ruslan U. -- Candidate of Chemical Sciences, Associate Professor of the Department of Physical and Analytical Chemistry of VSUIT, Director of Sensorika - New Technologies LLC, Voronezh, E-mail: rus_270487@mail.ru

Menzhulina Darya A. - pediatrician, endocrinologist of Voronezh Children's Clinical Hospital of VSMU named after N.N. Burdenko, Voronezh, Email: darinochka_08@mail.ru 